\title{
Fish Swim Bladder-Derived Porous Carbon for Defluoridation at Potable Water pH
}

\author{
John Karuga1, Yusufu A. C. Jande1, Hee T. Kim² ${ }^{2}$ Cecil K. King' ondu ${ }^{1,3 *}$ \\ ${ }^{1}$ Department of Materials and Energy Science and Engineering, Nelson Mandela African Institution of Science and Technology, Arusha, \\ Tanzania \\ ${ }^{2}$ Department of Chemical Engineering, Hanyang University, Seoul, Republic of South Korea \\ ${ }^{3}$ Department of Chemistry, South Eastern Kenya University, Kitui, Kenya \\ Email: karuggah@gmail.com, yusufu.jande@nm-aist.ac.tz, khtaik@hanyang.ac.kr, *kithongo.king’ondu@nm-aist.ac.tz
}

How to cite this paper: Karuga, J., Jande, Y.A.C., Kim, H.T. and King'ondu, C.K. (2016) Fish Swim Bladder-Derived Porous Carbon for Defluoridation at Potable Water pH. Advances in Chemical Engineering and Science, 6, 500-514.

http://dx.doi.org/10.4236/aces.2016.64044

Received: September 1, 2016

Accepted: October 22, 2016

Published: October 25, 2016

Copyright $\odot 2016$ by authors and Scientific Research Publishing Inc. This work is licensed under the Creative Commons Attribution International License (CC BY 4.0).

http://creativecommons.org/licenses/by/4.0/

\begin{abstract}
The levels of fluoride in various ground water sources in East Africa are above the World Health Organization upper limit of $1.5 \mathrm{mg} / \mathrm{L}$. Research on diverse defluoridation technologies has proven that adsorption stands out as an affordable, efficient, and facile technology. Fish swim bladder-derived porous carbon (FBPC) activated by $\mathrm{KOH}$ and surface oxidized by nitric acid was successfully investigated as an adsorbent for defluoridation at portable water $\mathrm{pH}$. The FBPC was characterized by scanning electron microscopy (SEM), transmission electron microscopy (TEM), X-raydiffraction (XRD) and energy dispersive spectroscopy (EDS). Batch methods were used to study physiochemical parameters viz., initial fluoride concentration, temperature, adsorbate dosage, contact time and $\mathrm{pH}$. Freundlich, Temkin, Langmuir and Dubinin-Radushkevich isotherms were plotted and analyzed to understand the adsorption process. Bangham, Weber Morris, pseudo first and second-order models were used to elucidate the kinetics of adsorption. Optimal conditions for fluoride removal were found to be: $\mathrm{pH}$ of 6 , FBPC adsorbent dose of $5.0 \mathrm{~g} / \mathrm{L}$ and contact time of $50 \mathrm{~min}$. Flouride adsorption followed pseudo second-order kinetic model and Langmuir isotherm best describes the adsorption process.
\end{abstract}

\section{Keywords}

Defluoridation, Adsorption, Fish Swim Bladder, Porous Carbon, Fluoride

\section{Introduction}

In response to the widespread geogenic and anthropogenic contamination of water sources, considerable efforts have been put into the development of water purification 
strategies that can meet the present global drinking water challenges. Ground water within the East Africa Rift Valley, one of the world's known high fluoride belt, is contaminated with high fluoride levels beyond the World Health Organization (WHO) limit of $1.5 \mathrm{mg} / \mathrm{L}$. Values of up to $46 \mathrm{mg} / \mathrm{L}$ have been reported in ground drinking water sources in Northern Tanzania [1]. High levels beyond $10 \mathrm{mg} / \mathrm{L}$ lead to crippling fluorosis [2]. Short term exposure to high doses of fluoride can exterminate the kidney function [3]. Also, fluoride inhibits the normal functioning of the brain [3]. Moreover, fluoride has been associated with the increased prevalence of Down's syndrome and sleep deprivation [4].

A number of techniques have been reported for the removal of fluoride from water such as nanofiltration [5], polyaniline modified electrode reactor [6], electrodialysis [7], Donnan dialysis [8], electrocoagulation [9], reverse osmosis [10], and adsorption [11]. However, these techniques are expensive and require electricity which is not available in most rural areas [3].

Adsorption has been shown to be cheap and convenient for defluoridation [12]. Adsorbents such as activated alumina [12], bone char [13], regenerated bone char [2], chitosan [14], fired clay chips [15], fly ash [16], and granular activated carbon coated with manganese oxides [17] have shown good potential in fluoride removal. Nevertheless, these adsorbents have low fluoride sorption capacity, work at high dosage [18], operate in low $\mathrm{pH}$ [19] which is not suitable for drinking water, and some like bone char are faced with socio-ethical issues.

In pursuit of an affordable and environmentally benign adsorbent with high fluoride sorption capacity for water defluoridation, fish swim bladder-derived porous carbon (FBPC) has been developed in this study. The fish bladder waste was chosen due to its low cost, newness as a porous carbon precursor and availability given that it is discarded as waste in East African countries. Total annual fish catch in Lake Victoria is approximately 1 million ton [20] [21]. Taking into account that fish swim-bladder constitutes approximately $2.3 \%$ of the total fish weight [22], an annual quantity of 24,405 ton of fish swim bladder is produced within the lake region. The FBPC showed high fluoride sorption capacity of $1.43 \mathrm{mg} / \mathrm{g}$ at very low dosage $(5.0 \mathrm{~g} / \mathrm{L})$ compared to 0.76 $\mathrm{mg} / \mathrm{g}$ and $10 \mathrm{~g} / \mathrm{L}$ for adsorbents previously reported [23].

\section{Materials and Methods}

\subsection{Preparation of Fish Swim Bladder-Derived Porous Carbon}

Carbonization: The fish bladders collected from the shores of Lake Victoria, Tanzania were washed with distilled water and dried for $24 \mathrm{~h}$ at $80^{\circ} \mathrm{C}$ in the oven, then carbonized between $400^{\circ} \mathrm{C}$ and $700^{\circ} \mathrm{C}$ in a furnace for $2 \mathrm{~h}$. The resultant carbon was then suspended in potassium hydroxide $(\mathrm{KOH})$ solution. The mixture was sonicated for $2 \mathrm{~h}$ then dried at $100^{\circ} \mathrm{C}$. The mass ratio of $\mathrm{KOH} /$ fish bladder carbon (FBPC) was 1:1, 2:1 and 3:1. Dry KOH/FBPC was then activated between $400^{\circ} \mathrm{C}$ and $700^{\circ} \mathrm{C}$ for a period of 1 $\mathrm{h}$ in a tube furnace under nitrogen [24]. After, the samples were washed with $1 \mathrm{M} \mathrm{HCl}$ and distilled water until neutral $\mathrm{pH}$ and dried $60^{\circ} \mathrm{C}$ for $24 \mathrm{~h}$. The activated are hereafter 
labeled X-FBPC-1, 2, or 3 as presented in Table 1. X represents the activation temperature, while the numbers represent the $\mathrm{KOH}$ to fish bladder ratios. Surface oxidation: 2 $\mathrm{g}$ of $\mathrm{KOH}$ activated FBPC samples were mixed with $100 \mathrm{~mL}$ of concentrated nitric acid and stirred for $3 \mathrm{~h}$ at $120^{\circ} \mathrm{C}$ [25]. The samples were then filtered and washed with distilled water till neutral $\mathrm{pH}$, and dried at $100^{\circ} \mathrm{C}$ in air. The purpose of surface oxidation was to introduce active oxygen moieties such as $-\mathrm{OH},-\mathrm{COOH}$, and - $\mathrm{O}-$ on the surface and thus make the carbon materials more hydrophilic [26].

\subsection{Materials Characterization and Fluoride Removal Studies}

Materials characterization: Scanning Electron Microscope (SEM) Model S-4800; Transmission electron microscope (TEM) JEOL 2010; Quantochrome Autosorb iQ2 gas sorption analyzer; and X-Ray Diffractometer (XRD), Rigaku Ultima IV system with $\mathrm{Cu}$ $\mathrm{K}$-alpha radiation were used to characterize the carbon samples. Batch fluoride removal experiments: Fluoride Stock solution of $100 \mathrm{mg} / \mathrm{L}$ was prepared by dissolving anhydrous sodium fluoride in distilled water. $200 \mathrm{~mL}$ working/test solutions with minimum fluoride concentration of $1.5 \mathrm{mg} / \mathrm{L}$ and maximum concentration of $13.5 \mathrm{mg} / \mathrm{L}$ were prepared from stock solution. $50 \mathrm{~mL}$ of the test solutions were then pipette into separate conical flasks and varying amounts of adsorbent ( 1 to $7 \mathrm{~g}$ ) were added. The adsorbate-adsorbent mixtures were then agitated for 10 to $70 \mathrm{~min}$, at room temperature and at $30^{\circ} \mathrm{C}, 40^{\circ} \mathrm{C}, 50^{\circ} \mathrm{C}$, and $60^{\circ} \mathrm{C}$ using a hot plate equipped with magnetic stirrer. Upon the lapse of the desired contact time, the adsorbents were filtered using filter paper (Whatman No.42). Total ionic strength adjustment buffer (TISAB) was prepared according to the procedure outlined in ASTM D 1179. TISAB was used since it enhances the precision of fluoride readings by concealing chemical interferences such as those of $\mathrm{OH}$-species in the test solution [17]. $5 \mathrm{~mL}$ of the filtrate and $5 \mathrm{~mL}$ of TISAB solution were pipette into a plastic beaker. The resultant solution was mixed thoroughly and then Mettler Toledo ion selective electrode was used to quantify the residual fluoride ions [27]. Analytical grade reagents from lobachemie we used in this study.

Percent fluoride removal analysis. The percentage of fluoride removed and total amount adsorbed (mg/g) was calculated using Equations (1) and (2), respectively [24].

$$
\begin{gathered}
\% R=\frac{\left(C_{i}-C_{e}\right)}{C_{i}} \times 100 \\
q_{e}=\frac{C_{i}-C_{e}}{m}
\end{gathered}
$$

Table 1. Temperatures and $\mathrm{KOH}$ ratios for FBPC synthesis.

\begin{tabular}{ccccc}
\hline \multirow{2}{*}{$\mathrm{C}: \mathrm{KOH}$} & \multicolumn{4}{c}{ Temperature $\left({ }^{\circ} \mathrm{C}\right)$} \\
\cline { 2 - 5 } & 400 & 500 & 600 & 700 \\
\hline $1: 1$ & $400-\mathrm{FBPC}-1$ & $500-\mathrm{FBPC}-1$ & $600-\mathrm{FBPC}-1$ & $700-\mathrm{FBPC}-1$ \\
$1: 2$ & $400-\mathrm{FBPC}-2$ & $500-\mathrm{FBPC}-2$ & $600-\mathrm{FBPC}-2$ & $700-\mathrm{FBPC}-2$ \\
$1: 3$ & $400-\mathrm{FBPC}-3$ & $500-\mathrm{FBPC}-3$ & $600-\mathrm{FBPC}-3$ & $700-\mathrm{FBPC}-3$ \\
\hline
\end{tabular}


The initial concentration, equilibrium concentration, amount adsorbed and mass are denoted as $C_{i} C_{e}, q_{e}$ and $m$, respectively.

\section{Results and Discussion}

\subsection{Materials Characterization}

Results for sample 600-FBPC-3 which demonstrated optimal defluoridation performance are discussed below. Figure 1(a) is an image of the fish swim bladder precursor. SEM was used to obtain topographical and morphological information for FBPC. SEM micrographs in Figure 1(b) show the surface and cross-sectional morphology of FBPC before chemical activation. Figures $1(\mathrm{c})$-(d) shows the surface and cross-sectional morphology of FBPC after chemical activation with various magnifications. The micrographs show that chemical activation with $\mathrm{KOH}$ creates an extensive network of randomly distributed nanoscale pores that contribute to the increased surface area of the material compared to unactivated carbon [28]. TEM was employed for further morphological and crystal structure studies. The TEM image in Figure 1(e) further corroborates SEM results by showing porous microstructure which is highly disordered. The XRD pattern in Figure 1(f) shows two peaks at $\sim 23^{\circ}$ and $\sim 43^{\circ} 2-\theta$. This diffraction pattern is consistent with amorphous graphitic carbon [29]. The BET surface area of the unactivated fish swim bladder carbon materials was found to be $13.88 \mathrm{~m}^{2} / \mathrm{g}$. Adsorption/desorption and pore size distribution graphs are in the supporting information 1. Upon activation with $\mathrm{KOH}$, surface area increased to $210.78 \mathrm{~m}^{2} / \mathrm{g}$ for 600 -

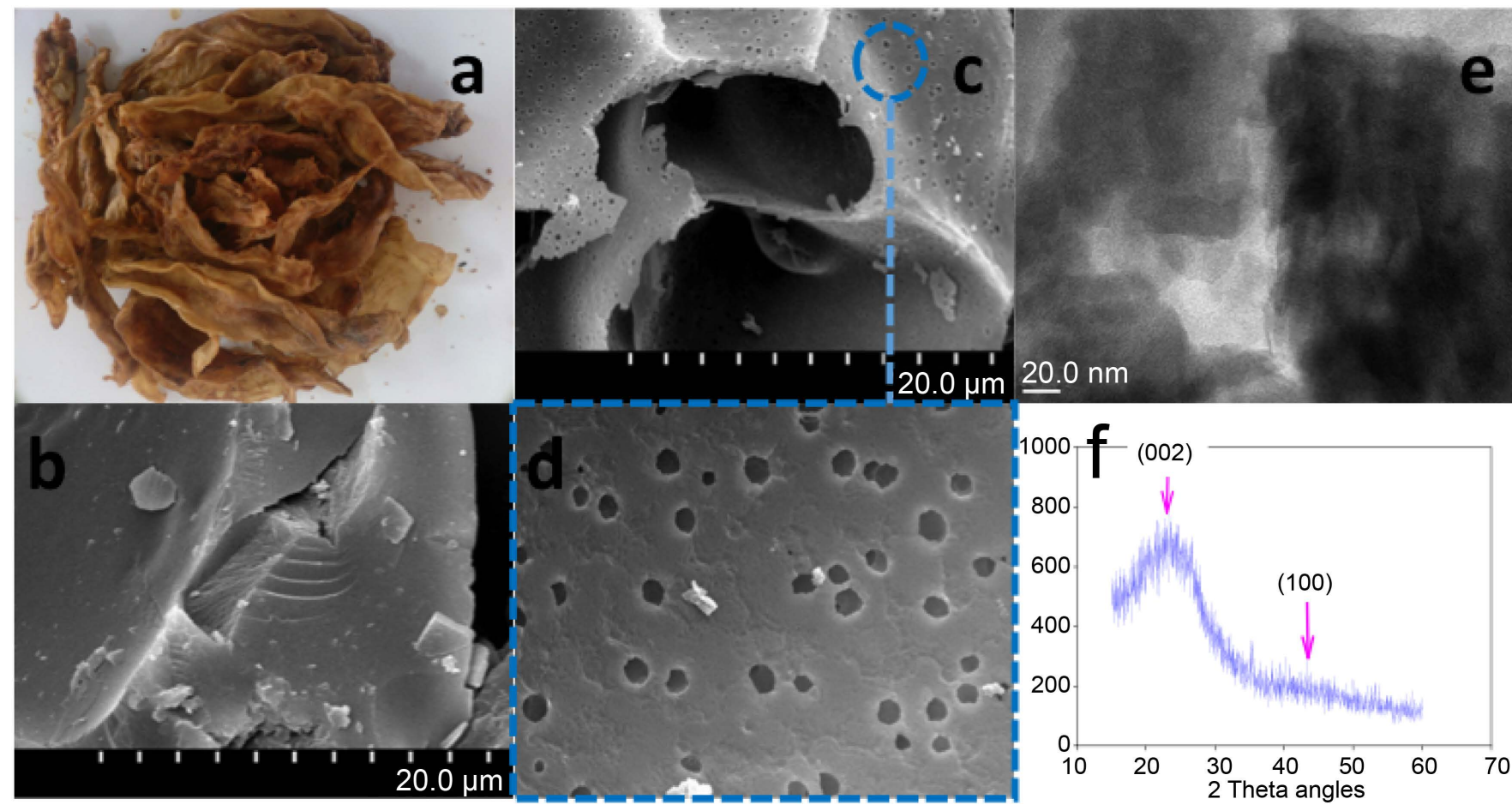

Figure 1. (a) Optical image of dried fish swim bladder precursor, (b) SEM image of unactivated 600-FBC, (c) SEM images of 600-FBPC-3, (d) Pores on 600-FBC-3 due to activation, (e) TEM image of 600-FBPC-3 and (f) XRD diffraction pattern of 600-FBPC-3. 

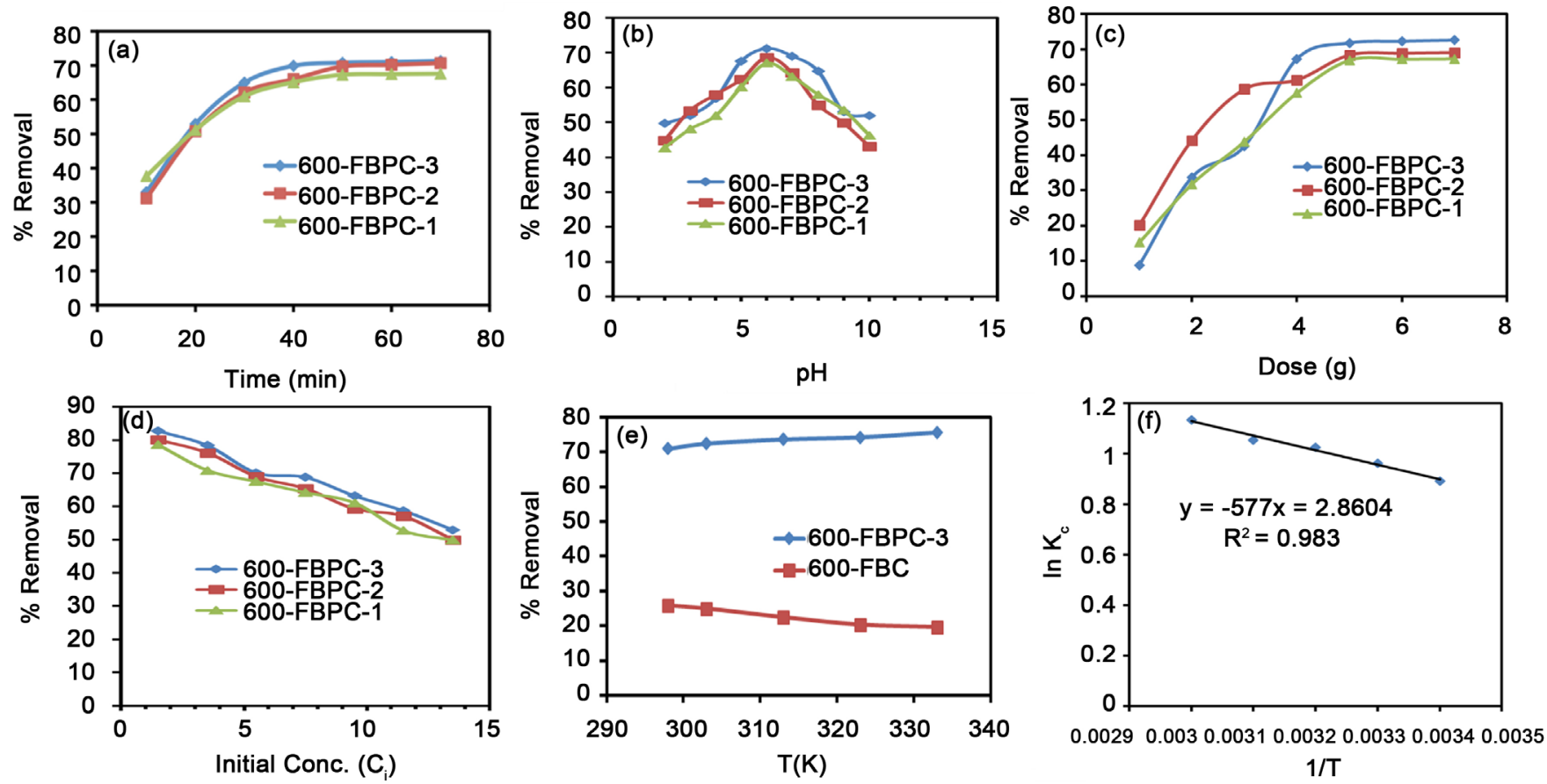

Figure 2. Effect of different parameters on fluoride removal efficiency (\% R), (a) contact time, (b) pH, (c) dose, (d) initial adsorbate concentration, (e) temperature, and (f) Thermodynamics of fluoride adsorption on FBPC. 
are given in Figure 2(b). Percent fluoride removal increased with increase in $\mathrm{pH}$ up to $\mathrm{pH}$ of 6 after which it decreased monotonically with increase in $\mathrm{pH}$. This phenomenon could be explained from point of zero charge (PZC) standpoint. PZC was derived from experimental setup done according to the procedure outlined by [31]. A value of $\mathrm{pH} 8.9$ was obtained, which is within the range of PZC values reported for carbon-rich materials [32]. The optimal defluoridation $\mathrm{pH}$ for FBPC is 6 . At a $\mathrm{pH}$ less than the PZC, the net charge on the surface of FBPC is positive due to the presence of abundant $\mathrm{H}^{+}$ions. This therefore favors adsorption of fluoride ions through coulombic attraction [24]. At very low $\mathrm{pH}$ values fluoride ion adsorption is unfavorable since fluoride ions convert to neutral hydrogen fluoride (HF has a pKa of 3.18) which hinders anion exchange. Deprotonation of fluoride adsorption sites occurs at high $\mathrm{pH}$ values, reducing the amount of fluoride adsorbed [33]. Moreover, an increased competition for binding sites between $\mathrm{OH}^{-}$and $\mathrm{F}^{-}$at basic $\mathrm{pH}$ lowers the quantity of fluoride adsorbed [17].

\subsubsection{Effect of Contact Time}

Contact time was varied between 10 and $70 \mathrm{~min}$, at room temperature, fluoride concentration of $5.5 \mathrm{mg} / \mathrm{L}$, and $\mathrm{pH}$ of 6 . An increase in contact time from 10 to $50 \mathrm{~min}$ was found to afford an increase in percent fluoride removal from $33 \%$ to $71 \%$. Extending the contact time led to a drop in boundary layer resistance to mass transfer and increased the solution's ion mobility [34]. Beyond $50 \mathrm{~min}$, the rate of fluoride adsorption plateaus. This was attributed to the fact that in the beginning, there were many adsorption sites available which gradually decrease in number with increase in contact time as more fluoride got adsorbed on the FBPC. From graph in Figure 2(a), it can be seen that 600-FBPC-3 exhibited relatively higher percent fluoride removal (71.3\%) than 600FBPC-1 (67.6\%) and better sorption capacity at similar contact time as a result of higher porosity.

\subsubsection{Effect of Initial Concentration}

To study the effect of initial fluoride ion concentration on percent removal efficiency, experiments were conducted by varying the initial concentration between 1.5 and 13.5 $\mathrm{mg} / \mathrm{L}$, at room temperature, contact time of $50 \mathrm{~min}, \mathrm{pH}$ of 6 , and FBPC dose of $5.0 \mathrm{~g} / \mathrm{L}$. From Figure 2(d), maximum removal efficiencies of $83 \%, 80.1 \%$, and $78.6 \%$ for 600 FBPC-3, 600-FBPC-2, and 600-FBPC-1, correspondingly, were observed with an initial concentration of $1.5 \mathrm{mg} / \mathrm{L}$. On the contrary, 600-FBPC-3, 600-FBPC-2, and 600-FBPC1 afforded percent removal of $49 \%, 50 \%$ and $53 \%$, respectively; at $13.5 \mathrm{mg} / \mathrm{L}$ initial concentration of fluoride ions and the large quantity of adsorbate molecules present at higher initial concentrations, led to a decline in the total number of binding sites available for adsorption [35].

\subsubsection{Effect of Temperature}

To study the effect of temperature on fluoride adsorption, experiments were carried out at room temperature $\left(25^{\circ} \mathrm{C} \pm 3^{\circ} \mathrm{C}\right), 30^{\circ} \mathrm{C}, 40^{\circ} \mathrm{C}, 50^{\circ} \mathrm{C}$, and $60^{\circ} \mathrm{C}, \mathrm{pH}$ of 6 , adsorbent dose of $5.0 \mathrm{~g} / \mathrm{L}$ and fluoride concentration of $5.5 \mathrm{mg} / \mathrm{L}$. Fluoride removal decreased with temperature for the un-activated FBPC, Figure 2(e). This was probably due de- 
sorption of fluoride ions due to lack of strong surface active sites. Unlike un-activated carbon, activated FBPC samples showed marginal increase in removal efficiency (\% R) with temperature, Figure 2(e). This was due to the increased fluoride ions mobility leading to enhanced ions diffusion into the porous network of the adsorbent. Thermodynamics of fluoride adsorption which further corroborates temperature effect results is presented in Figure 2(f). Gibbs free energy, change in entropy and change in enthalpy are calculated using the following equations:

$$
\begin{gathered}
\Delta G=-R T \ln K_{c} \\
\ln K_{c}=\frac{\Delta S}{R}-\frac{\Delta H}{R}\left(\frac{1}{T}\right) ; \\
\Delta G=\Delta H-T \Delta S
\end{gathered}
$$

where $K_{c}=C_{a} / C_{e}$ and $C_{a}$ is the fluoride concentration in the adsorbent at equilibrium; $C_{e}$ is the fluoride concentration in solution at equilibrium. $\Delta G$ is the change in Gibbs free energy, $R$ is the gas constant $(8.314 \mathrm{~J} / \mathrm{molK})$ and $T$ is temperature in Kelvin. Change in enthalpy $(\Delta H)$ in our study was $+4.80 \mathrm{~kJ} / \mathrm{mol}$. This was indicative of an endothermic process. Since $\Delta H$ was within the range of 1 to $8 \mathrm{~kJ} / \mathrm{mol}$, the adsorption occurred mainly through physiosorption [36]. Values of Gibbs free energy $(\Delta G)$ were found to be negative. This confirmed the feasibility and spontaneity of the adsorption process. Change in entropy $(\Delta S)$ which quantifies the amount of energy of atoms and molecules spread out in adsorption process, had a positive value, indicating that the adsorbent had a strong affinity for fluoride ions [37].

\subsection{Adsorption Isotherm Study}

Adsorption isotherms show the correlation between the amount of adsorbate and its concentration at equilibrium at constant temperature [23]. In our work, Langmuir, Freundlich, Dubinin-Radushkevich, and Temkin adsorption isotherms were used to elucidate the adsorption phenomenon.

\subsubsection{Freundlich Isotherm}

Isotherm equation: $\log \left(q_{e}\right)=\log k_{f}+\left(\frac{1}{n}\right) \log C_{e}$

where $q_{e}(\mathrm{mg} / \mathrm{g})$ is the amount of fluoride adsorbed per unit mass of adsorbent, $C_{e}$ $(\mathrm{mg} / \mathrm{L})$ is the equilibrium/final fluoride concentration, $1 / n$ is the adsorption intensity, and $K_{f}$ is the adsorption capacity. Values of $1 / n$ and $K_{f}$ are 0.553 and 0.581 , respectively. A plot of $\log \left(q_{e}\right)$ versus $\log \left(C_{e}\right)$ in Figure 3(a), gave a straight line. This establishes the suitability of Freundlich isotherm which confirm the diversity of fluoride adsorption sites [38].

\subsubsection{Langmuir Isotherm}

Isotherm equation: $\frac{C_{e}}{q_{e}}=\left(\frac{a_{L}}{K_{L}}\right) C_{e}+\frac{1}{K_{L}}$

Langmuir constant $K_{L}(\mathrm{~L} / \mathrm{mg})$ is connected to free energy of adsorption [39], while $a_{L}$ 

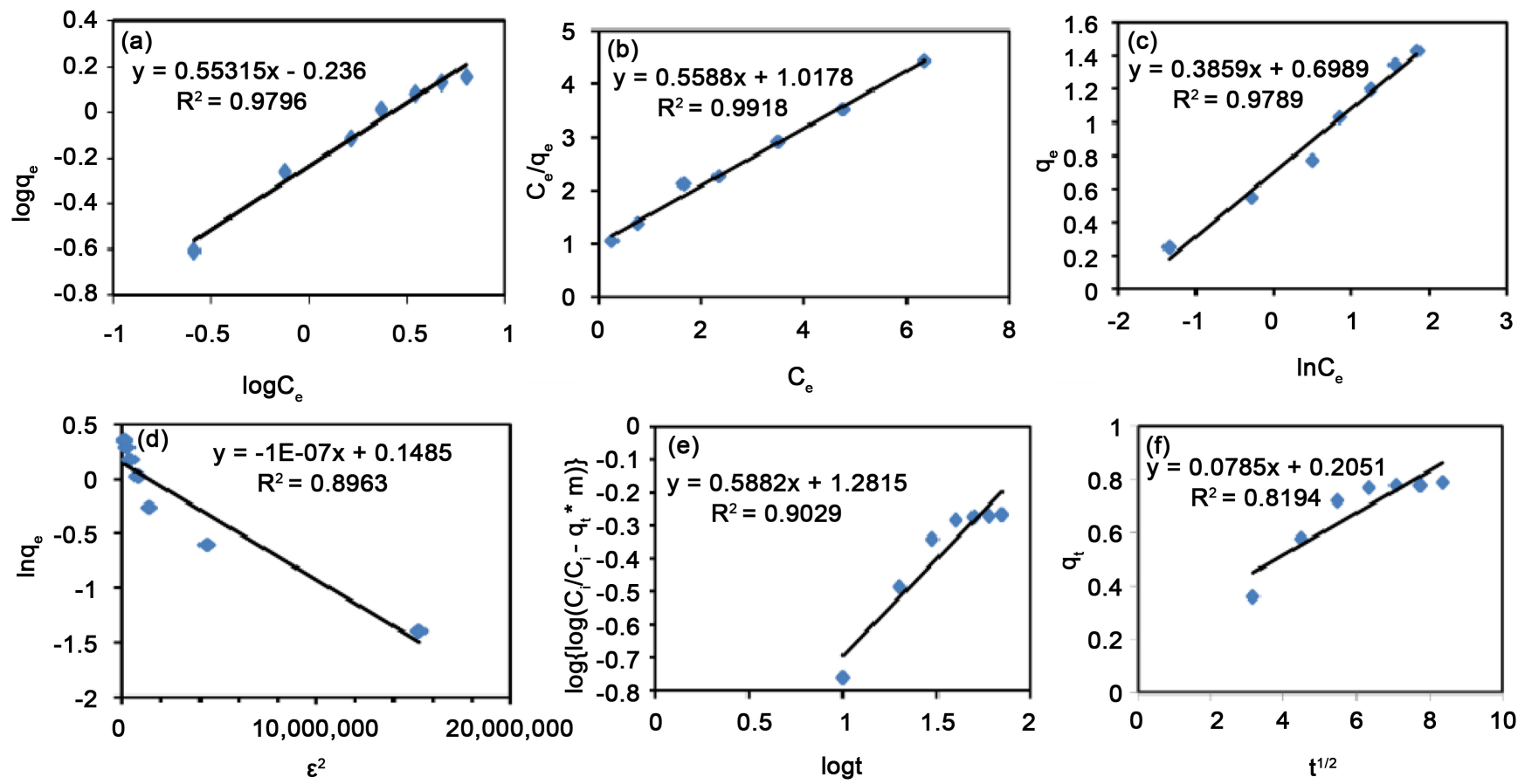

Figure 3. (a) Freundlich adsorption isotherm, (b) Langmuir adsorption isotherm, (c) Temkin adsorption isotherm, (d) Dubinin-Radushkevich adsorption isotherm, (e) Bangham's pore diffusion model, and (f) Weber Morris diffusion model.

is a Langmuir constant related to capacity of adsorption. $a_{L}$ and $k_{L}$ can be calculated from the slope and intercept, respectively. The dimensionless parameter $R_{L}$, which defines the essential features of Langmuir isotherm can be expressed as follows:

$$
R_{L}=1 /\left(1+a_{L} C_{i}\right)
$$

The value of $R_{L}$ indicates the shape of Langmuir isotherm to be either unfavourable $\left(R_{L}>1\right)$, linear $\left(R_{L}=1\right)$, irreversible $\left(R_{L}=0\right)$ or favourable $\left(0<R_{L}<1\right)$ (27). Moreover, a smaller $R_{L}$ value indicates a highly favourable adsorption [40]. A plot of $C_{e} / q_{e}$ versus $C_{e}$ is shown in Figure 3(b). Calculated $R_{L}$ value was 0.26 which is within the favourable range. The correlation coefficients $\left(R^{2}\right)$ of Freundlich and Langmuir isotherm models were 0.98 and 0.99 , respectively. Therefore, Langmuir isotherm model was more ideal than Freundlich isotherm in analyzing the adsorption phenomena in our study. High $R^{2}$ values for Langmuir isotherm suggests a finite number of even adsorption sites and the lack of lateral interactions [38].

\subsubsection{Temkin Isotherm}

Isotherm equation: $q_{e}=B \ln C_{e}+B \ln A$ where $B=R T / b$.

A factor associated with heat of sorption $B$ has a value of $0.386 \mathrm{~J} / \mathrm{mol}$ and $A$ is an isotherm constant with a value of $6.117 \mathrm{~L} / \mathrm{g}$. A plot of $q_{e}$ versus In $C_{e}$ is depicted in Figure $3(c)$. This isotherm is suitable in describing middle-range ion concentrations [41].

\subsubsection{Dubinin-Radushkevich (D-R) Isotherm}

Isotherm equation: $\ln q_{e}=-\beta \varepsilon^{2}+\ln Q_{m}$ 
where $\varepsilon=R T \ln \left(1+1 / C_{e}\right), \beta$ is a constant related to energy, $E=1 / \sqrt{2 \beta}$ and $Q_{m}$ (mol/g) is the D-R monolayer adsorption capacity. $\varepsilon$ is Polanyi potential and $T$ is temperature. D-R isotherm plot is depicted in Figure 3(d). Calculated value of D-R free energy ( $E$ ) was $2.162 \mathrm{~kJ} / \mathrm{mol}$. When $E<8 \mathrm{~kJ} / \mathrm{mol}$, physiosorption is preeminent over chemisorption and ion exchange [42]. Physiosorption is a result of weak forces i.e. Van der Waals forces between the adsorbate and adsorbent.

\subsection{Kinetic Study of Adsorption}

Kinetics of adsorption characterizes the time for adsorption and rate of solute uptake. To better understand the kinetics of fluoride adsorption in this study, the following kinetic models were analyzed: Bangham's pore diffusion model, Weber and Morris intra-particle diffusion model, pseudo first-order, and pseudo second-order model.

\subsubsection{Bangham's Pore Diffusion}

Model equation: $\log \left[\log \left(C_{i} / C_{i}-q_{t} m\right)\right]=\log \left(k_{o} / 2.303 V\right)+a \log (t)$

where $k_{o}$ is a constant for the Bangham's pore diffusion rate and $\alpha$ is a constant. A plot of $\log \left[\log \left(C_{i} / C_{i}-q_{t} m\right)\right]$ versus $\log (t)$ at contact time ranging from 10 to $70 \mathrm{~min}$ is presented in Figure 3(e). The data points are not linear, implying that adsorption is not limited by pore diffusion [35]. Bangham's slope with values approximating $0.6-0.7$ correspond to diffusion processes, while values less than 0.5 indicate chemisorptions [43]. The slope has a value of 0.588 , thus validating Dubinin-Radushkevich's results that confirmed adsorption largely occurs through physiosorption.

\subsubsection{Weber-Morris Intraparticle Diffusion Model}

Model equation: $q_{t}=k_{i p} t^{1 / 2}+C$.

Weber and Morris diffusion rate constant $k_{i p}$ value is derived from the slope in the plot of $\left(q_{t}\right)$ versus $t^{1 / 2}$. The diffusion model plot is displayed in Figure 3(f). A plot of the first three linear points gave a value of $0.156 \mathrm{mg} / \mathrm{g} \min ^{1 / 2}$ for $k_{i p}$. Since the line passes across the origin intra-particle diffusion is the rate controlling step [39]. At the beginning there is a higher rate of adsorption then later it changes to rather low to constant adsorption. This can be explained by the freely accessible external adsorption sites (macropores) at the start [44], which facilitate boundary layer diffusion [33]. This model has two major drawbacks: adsorbent particles should have a constant size and the equilibrium between the adsorbate and adsorbent must obey Henry's law [45].

\subsubsection{Pseudo First Order and Second Order Model}

First-order model equation: $\log \left(q_{e}-q_{t}\right)=\log q_{e}-k_{i} t / 2.302$ and $t / q_{t}=1 / k_{2} q_{e}^{2}-\left(1 / q_{e}\right) t$ is second-order model equation. Value of first-order rate constant $k_{i}$ was 0.101 from the slope of $\log \left(q_{e}-q_{t}\right)$ versus $t$ in Figure 4(a). $R^{2}$ values close to one (0.959) indicate that adsorption favors physiosorption over chemisorption. A plot of $t / q_{t}$ versus $t$ in Figure 4(b) yielded a plot with a straight line, confirming the suitability of pseudo second order model. Value of second-order rate constant $k_{2}$ was 0.081 as determined from the graph intercept. Initial adsorption rate $\left(k_{2} q_{e}^{2}\right)$ was 0.074 . 

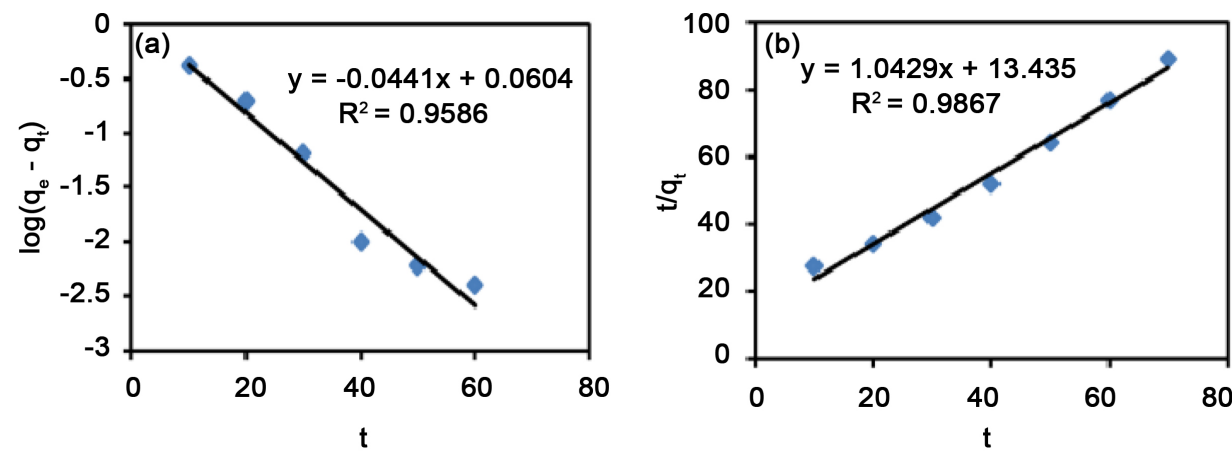

Figure 4. Kinetic order models, (a) Pseudo first order, (b) Pseudo second order.

This model replicated the adsorption phenomena predicted by intra-particle diffusion model for adsorbents composed of uniform and spherical particles. The high $R^{2}$ value in second order model indicates that there is some degree of chemisorption in the adsorption process.

In this study Langmuir isotherm and pseudo second-order best described the adsorption process. Freundlich, Temkin, Langmuir and Dubinin-Radushkevich adsorption isotherms yielded the following correlation coefficient values: 0.98, 0.992, 0.979, and 0.896, respectively. On the other hand, Weber-Morris, Bangham's pore diffusion model, pseudo first-order, and pseudo second order gave 0.820, 0.903, 0.959, and 0.987, respectively as the correlation coefficient values. $R^{2}$ values closest to unity confirm the suitability of a particular isotherm and kinetic model in describing the adsorption phenomena.

Furthermore, the performance of the prepared adsorbent (FBPC) was compared with other adsorbents reported in literature. The comparison was based on physicochemical parameters such as $\mathrm{pH}$, adsorbent dose, initial concentration, amount adsorbed, percentage removal, and contact time. The results are presented in Table 2. From the table, it can be deduced that FBPC is a more ideal adsorbent than regenerated bone char, granular AC and AC from bagasse, wheat straw and saw dust in terms of percentage removal of fluoride, surface area, residence time and optimal $\mathrm{pH}$. The optimal $\mathrm{pH}$ for defluoridation by $\mathrm{KMnO}_{4}$ modified carbon derived from rice straw is 2, making it non-ideal for drinking water applications.

Optimal contact time of FBPC is comparable to that of immobilized activated alumina, regenerated bone char and AC from bagasse, saw dust and wheat straw. AC from Zircon impregnated coconut shell, banana peel and Eichhorniacrassipes require long contact time ( $12 \mathrm{~h}$ and beyond) which is not ideal for immediate applications. The shortcomings of the above mentioned materials give FBPC an edge in defluoridation use.

\section{Conclusion}

Novel fish swim bladder-derived adsorbent materials for water defluoridation have been successfully prepared. Optimal conditions for defluoridation were found to be $\mathrm{pH}$ 
Table 2. Comparison of FBPC materials with other adsorbents reported in the literature.

\begin{tabular}{|c|c|c|c|c|c|c|c|c|}
\hline No. & Adsorbent & $\mathrm{pH}$ & $\begin{array}{l}\text { Dose } \\
(\mathrm{g} / 1)\end{array}$ & $\begin{array}{c}C_{i} \\
(\mathrm{mg} / \mathrm{l})\end{array}$ & $\% \mathrm{R}$ & $\begin{array}{c}Q_{e} \\
(\mathrm{mg} / \mathrm{g})\end{array}$ & $\begin{array}{l}\text { Contact time } \\
(\mathrm{min})\end{array}$ & Ref. \\
\hline 1 & $\begin{array}{l}\text { Granular AC coated with } \\
\qquad \mathrm{MnO}_{2}\end{array}$ & 5.2 & 5.0 & $10-30$ & - & 2.24 & 150 & [17] \\
\hline 2 & $\begin{array}{c}\text { Immobilized activated } \\
\text { Alumina \& Activated } \\
\text { carbon }\end{array}$ & 7 & 10.0 & $0.5-12$ & $\begin{array}{l}95 \\
84\end{array}$ & $\begin{array}{l}0.76 \\
0.47\end{array}$ & $\begin{array}{l}60 \\
90\end{array}$ & [23] \\
\hline 3 & $\begin{array}{c}\text { Granular AC \& } \\
\text { Domestic sewage sludge }\end{array}$ & 7 & $\begin{array}{l}4.0 \\
3.0\end{array}$ & 5.0 & $\begin{array}{l}70 \\
82\end{array}$ & - & $\begin{array}{l}120 \\
120\end{array}$ & [46] \\
\hline 3 & $\begin{array}{c}\mathrm{KMnO}_{4} \text { modified } \\
\mathrm{AC} \text { from rice }\end{array}$ & 2 & 2.5 & $5-20$ & $>70$ & 15.9 & 180 & [19] \\
\hline 4 & Regenerated bone char & - & $6-25$ & 21.26 & 70.64 & 0.75 & 60 & {$[2]$} \\
\hline 5 & $\begin{array}{c}\text { Bagasse AC, } \\
\text { Saw dust AC \& } \\
\text { Wheat straw AC }\end{array}$ & 6 & 4.0 & 5.0 & $\begin{array}{l}56.4 \\
49.3 \\
40.2\end{array}$ & $\begin{array}{l}1.15 \\
1.73 \\
1.93\end{array}$ & 60 & [47] \\
\hline 6 & Eichhornia Crassipes AC & 5.5 & $10-40$ & $2-25$ & 98.28 & $0.52-1.54$ & 1440 & {$[48]$} \\
\hline 7 & $\begin{array}{l}\text { Zircon impregnated } \\
\text { coconut shell AC }\end{array}$ & 4 & 10.0 & 10.0 & $>90$ & $0.9-0.99$ & 720 & [49] \\
\hline 8 & $\begin{array}{c}\text { Banana peel AC \& } \\
\text { Coffee husk AC }\end{array}$ & 2 & $\begin{array}{l}96.0 \\
72.0\end{array}$ & 5 & $80-84$ & $\begin{array}{l}0.18 \\
0.14\end{array}$ & $\begin{array}{l}780 \\
180\end{array}$ & [18] \\
\hline 9 & $\begin{array}{c}\text { Fish Swim Bladder } \\
\text { Carbon }\end{array}$ & 6 & 5.0 & $1.5-13.5$ & 82.7 & 1.43 & 50 & \\
\hline
\end{tabular}

of 6, FBPC dose of $5.0 \mathrm{~g} / \mathrm{L}$, and a contact time of $50 \mathrm{~min}$. Adsorption process best fitted Langmuir isotherm model. Correlation coefficient value for Langmuir (0.99) was higher than for other isotherm models, thus confirming a monolayer adsorption [24]. Freundlich isotherm $\left(R^{2}=0.98\right)$ indicated that the adsorbent surface was heterogeneous. Kinetic investigation of the defluoridation process showed that the adsorption process followed pseudo second-order model. Peak removal efficiency of $82.7 \%$ was observed at $1.5 \mathrm{mg} / \mathrm{L}$ adsorbate concentration. Largest amount adsorbed was $1.43 \mathrm{mg} / \mathrm{g}$ at 13.5 $\mathrm{mg} / \mathrm{L}$ initial concentration.

\section{Acknowledgements}

The authors appreciate the financial support provided by The African Capacity Building Foundation (ACBF) through Nelson Mandela-African Institute of Science and Technology. Special thanks to Dr. Godlisten Shayo and Dr. Askwar Hilonga for their assistance in materials characterization.

\section{References}

[1] Thole, B. (2013) Ground Water Contamination with Fluoride and Potential Fluoride Removal Technologies for East and Southern Africa. Perspectives in Water Pollution [Internet]. INTECH Open Science, Blantyre, 66-90. 
http://www.intechopen.com/books/perspectives-in-water-pollution/ground-water-contami nation-with-fluoride-and-potential-fluoride-removal-technologies-for-east-and-so

[2] Kaseva, M.E. (2006) Optimization of Regenerated Bone Char for Fluoride Removal in Drinking Water: A Case Study in Tanzania. Journal of Water and Health, 4, 139-147.

[3] Tomar, V. and Kumar, D. (2013) A Critical Study on Efficiency of Different Materials for Fluoride Removal from Aqueous Media. Chemistry Central Journal, 7, 1. http://dx.doi.org/10.1186/1752-153X-7-51

[4] Jamode, A.V., Sapkal, V.S. and Jamode, V.S. (2004) Defluoridation of Water Using Inexpensive Adsorbents. Journal of the Indian Institute of Science, 84, 163-171.

[5] Nasr, A.B., Charcosset, C., Amar, R.B. and Walha, K. (2013) Defluoridation of Water by Nanofiltration. Journal of Fluorine Chemistry, 150, 92-97.

http://www.sciencedirect.com/science/article/pii/S0022113913000250 http://dx.doi.org/10.1016/j.jfluchem.2013.01.021

[6] Cui, H., Li, Q., Qian, Y., Tang, R., An, H. and Zhai, J. (2011) Defluoridation of Water via Electrically Controlled Anion Exchange by Polyaniline Modified Electrode Reactor. Water Research, 45, 5736-5744. http://www.ncbi.nlm.nih.gov/pubmed/21907382 http://dx.doi.org/10.1016/j.watres.2011.08.049

[7] Tahaikt, M., Achary, I., Menkouchi Sahli, M.A., Amor, Z., Taky, M., Alami, A., et al. (2004) Defluoridation of Moroccan Ground Water by Electrodialysis: Continuous Operation. Desalination, 167, 357. http://www.sciencedirect.com/science/article/pii/S0011916404003856 http://dx.doi.org/10.1016/j.desal.2004.06.145

[8] Hichour, M., Persin, F., Sandeaux, J. and Gavach, C. (1999) Fluoride Removal from Waters by Donnan Dialysis. Separation and Purification Technology, 18, 1-11. http://www.sciencedirect.com/science/article/pii/S1383586699000428 http://dx.doi.org/10.1016/S1383-5866(99)00042-8

[9] Hu, C.Y., Lo, S.L., Kuan, W.H. and Lee, Y.D. (2005) Removal of Fluoride from Semiconductor Wastewater by Electrocoagulation-Flotation. Water Research, 39, 895-901.

http://www.sciencedirect.com/science/article/pii/S0043135404005731 http://dx.doi.org/10.1016/j.watres.2004.11.034

[10] Arora, M., Maheshwari, R.C., Jain, S.K. and Gupta, A. (2004) Use of Membrane Technology for Potable Water Production. Desalination, 170, 105-112. http://dx.doi.org/10.1016/j.desal.2004.02.096

[11] Loganathan, P., Vigneswaran, S., Kandasamy, J. and Naidu, R. (2013) Defluoridation of Drinking Water Using Adsorption Processes. Journal of Hazardous Materials, 248-249, 1-19. http://www.sciencedirect.com/science/article/pii/S0304389412012113 http://dx.doi.org/10.1016/j.jhazmat.2012.12.043

[12] Wu, Y.C. and Nitya, A. (1979) Water Defluoridation with Activated Alumina. Journal of Environmental Engineering (ASCE), 105, 357-367. http://cedb.asce.org/cgi/WWWdisplay.cgi?8745

[13] Medellin-Castillo, N.A., Leyva-Ramos, R., Ocampo-Perez, R., Garcia de la Cruz, R.F., Aragon-Piña, A., Martinez-Rosales, J.M., et al. (2007) Adsorption of Fluoride from Water Solution on Bone Char. Industrial \& Engineering Chemistry Research, 46, 9205-9212. http://dx.doi.org/10.1021/ie070023n

[14] Jagtap, S., Thakre, D., Wanjari, S., Kamble, S., Labhsetwar, N. and Rayalu, S. (2009) New Modified Chitosan-Based Adsorbent for Defluoridation of Water. Journal of Colloid and Interface Science, 332, 280-290.

http://www.sciencedirect.com/science/article/pii/S0021979708014513 http://dx.doi.org/10.1016/j.jcis.2008.11.080 
[15] Moges, G., Zewge, F. and Socher, M. (1996) Preliminary Investigations on the Defluoridation of Water Using Fired Clay Chips. Journal of African Earth Sciences, 22, 479-482.

http://www.sciencedirect.com/science/article/pii/0899536296000309

http://dx.doi.org/10.1016/0899-5362(96)00030-9

[16] Chaturvedi, A.K., Yadava, K.P., Pathak, K.C. and Singh, V.N. (1990) Defluoridation of Water by Adsorption on Fly Ash. Water, Air, \& Soil Pollution, 49, 51-61.

http://link.springer.com/10.1007/BF00279509

http://dx.doi.org/10.1007/BF00279509

[17] Wang, S., Fan, M. and Gao, B. (2009) Characteristics and Defluoridation Performance of Granular Activated Carbons Coated with Manganese Oxides. Journal of Hazardous Materials, 168, 1140-1146. http://dx.doi.org/10.1016/j.jhazmat.2009.02.145

[18] Getachew, T., Hussen, A. and Rao, V.M. (2014) Defluoridation of Water by Activated Carbon Prepared from Banana (Musa paradisiaca) Peel and Coffee (Coffea arabica) Husk. International Journal of Environmental Science and Technology, 12, 1857-1866.

http://link.springer.com/10.1007/s13762-014-0545-8

http://dx.doi.org/10.1007/s13762-014-0545-8

[19] Daifullah, A.A.M., Yakout, S.M. and Elreefy, S.A. (2007) Adsorption of Fluoride in Aqueous Solutions Using $\mathrm{KMnO}_{4}$-Modified Activated Carbon Derived from Steam Pyrolysis of Rice Straw. Journal of Hazardous Materials, 147, 633-643. http://dx.doi.org/10.1016/j.jhazmat.2007.01.062

[20] LVFO (2014) State of Fish Stocks. Lake Victoria Fisheries Organization, East Africa. http://www.lvfo.org/index.php/lvfo/lvfo-secretariat/6-state-of-fish-stocks\#

[21] Lake Victoria Fisheries Organization (2013) Regional Status Report on Lake Victoria Bi-Ennial Frame Surveys between 2000 and 2012. Jinja, Uganda.

[22] Ogunja, J.C., Werimo, K.O. and Okemwa, E.N. (1990) A Case Study on High-Value Nile Perch Products. Proceedings of the Symposium on Post-Harvest Fish Technology, FAO, Cairo, Egypt. http://www.fao.org/docrep/005/t0606b/T0606B06.htm

[23] Rafique, A., Awan, M.A., Wasti, A., Qazi, I.A. and Arshad, M. (2013) Removal of Fluoride from Drinking Water Using Modified Immobilized Activated Alumina. Journal of Chemistry, 2013, Article ID: 386476.

[24] Suneetha, M., Sundar, B.S. and Ravindhranath, K. (2015) Removal of Fluoride from Polluted Waters Using Active Carbon Derived from Barks of Vitex negundo Plant. Journal of Analytical Science and Technology, 6, 15. http://dx.doi.org/10.1186/s40543-014-0042-1

[25] Stavropoulos, G.G., Samaras, P. and Sakellaropoulos, G.P. (2008) Effect of Activated Carbons Modification on Porosity, Surface Structure and Phenol Adsorption. Journal of Hazardous Materials, 151, 414-421. www.elsevier.com/locate/jhazmat http://dx.doi.org/10.1016/j.jhazmat.2007.06.005

[26] Moreno-Castilla, C., Lopez-Ramon, M.V. and Carrasco-Marin, F. (2000) Changes in Surface Chemistry of Activated Carbons by Wet Oxidation. Carbon, 38, 1995-2001. http://dx.doi.org/10.1016/S0008-6223(00)00048-8

[27] Hanumantharao, Y., Medikondu, K. and Kunta, R. (2012) Characterization and Defluoridation Studies of Active Carbon Derived from Typha Angustata Plants. Journal of Analytical Science \& Technology, 3, 167-181. http://dx.doi.org/10.5355/JAST.2012.167

[28] Chen, W.X., Zhang, H., Huang, Y. and Wang, W. (2010) A Fish Scale Based Hierarchical Lamellar Porous Carbon Material Obtained Using a Natural Template for High Performance Electrochemical Capacitors. Journal of Materials Chemistry, 20, 4773-4775. http://dx.doi.org/10.1039/c0jm00382d 
[29] Xu, J., Gao, Q., Zhang, Y., Tan, Y., Tian, W., Zhu, L. and Jiang, L. (2014) Preparing Two-Dimensional Microporous Carbon from Pistachio Nutshell with High Areal Capacitance as Supercapacitor Materials. Scientific Reports, 4, Article No. 5545.

[30] Killedar, D.J. and Bhargava, D. (1993) Effects of Stirring Rate and Temperature on Fluoride Removal by Fishbone Charcoal. Indian Journal of Environmental Health, 35, 81-87.

[31] El-Sayed, G.O., Yehia, M.M. and Asaad, A.A. (2014) Assessment of Activated Carbon Prepared from Corncob by Chemical Activation with Phosphoric Acid. Water Resources and Industry, 7-8, 66-75. http://linkinghub.elsevier.com/retrieve/pii/S2212371714000353

[32] Kosmulski, M. (2014) The pH Dependent Surface Charging and Points of Zero Charge. VI. Update. Journal of Colloid and Interface Science, 426, 209-212. http://dx.doi.org/10.1016/j.jcis.2014.02.036

[33] Rajkumar, S., Murugesh, S., Sivasankar, V. and Chaabane, T. (2015) Low-Cost Fluoride Adsorbents Prepared from a Renewable Biowaste: Syntheses, Characterization and Modeling Studies. Arabian Journal of Chemistry, in press.

[34] Kumar, P.S., Vincent, C., Kirthika, K. and Kumar, K.S. (2010) Kinetics and Equilibrium Studies of $\mathrm{Pb}_{2+}$ Ion Removal from Aqueous Solutions by Use of Nano-Silversol-Coated Activated Carbon. Brazilian Journal of Chemical Engineering, 27, 339-346. http://dx.doi.org/10.1590/S0104-66322010000200012

[35] Yaneva, Z.L., Koumanova, B.K. and Allen, S.J. (2013) Applicability Comparison of Different Kinetic/Diffusion Models for 4-Nitrophenol Sorption on Rhizopus oryzae Dead Biomass. Bulgarian Chemical Communications, 45, 161-168.

[36] Zelentsov, V. and Datsko, T. (2013) Thermodynamics of fluorine adsorption onto modified Trepel. Termotehnica, 1, 25-30.

[37] Kumar, V., Ali, I. and Kumar, V. (2007) Defluoridation of Wastewaters Using Waste Carbon Slurry. Water Research, 41, 3307-3316. http://dx.doi.org/10.1016/j.watres.2007.04.029

[38] Sabine, G. (2005) Equations and Models Describing Adsorption Processes in Soils. Chemical Processes in Soils. Soil Science Society of America, Wisconsin, 489-517.

[39] Yakout, S.M. and Elsherif, E. (2010) Batch Kinetics, Isotherm and Thermodynamic Studies of Adsorption of Strontium from Aqueous Solutions onto Low Cost Rice-Straw Based Carbons. Carbon-Science and Technology, 3, 144-153. http://www.applied-science-innovations.com

[40] Bousba, S. and Hassen, A. (2013) Adsorption of 2-Chlorophenol onto Sewage Sludge Based Adsorbent: Equilibrium and Kinetic Study. Chemical Engineering Transactions, 35, 859864. www.aidic.it/cet

[41] Kinniburgh, D.G. (1985) Isotherm. A Computer Program for Analyzing Adsorption Data. British Geological Survey, Wallingford.

[42] Jain, M., Garg, V.K. and Kadirvelu, K. (2009) Chromium (VI) Removal from Aqueous Solution, Using Sunflower Stem Waste. Journal of Hazardous Materials, 162, 365-372. http://dx.doi.org/10.1016/j.jhazmat.2008.05.048

[43] Marczewski, A.W. (2015) A Practical Guide to Isotherms of Adsorption on Heterogeneous Surfaces. http://sorption.org/awm/ads/Kinetics.htm\#kin-eqs

[44] Li, P.H.Y., Bruce, R.L. and Hobday, M.D. (1999) A Pseudo First Order Rate Model for the Adsorption of an Organic Adsorbate in Aqueous Solution. Journal of Chemical Technology and Biotechnology, 74, 55-59. http://dx.doi.org/10.1002/(SICI)1097-4660(199901)74:1<55::AID-JCTB984>3.0.CO;2-D

[45] Plazinski, W., Dziuba, J. and Rudzinski, W. (2013) Modeling of Sorption Kinetics: The Pseudo-Second Order Equation and the Sorbate Intraparticle Diffusivity. Adsorption, 19, 
1055-1064. http://dx.doi.org/10.1007/s10450-013-9529-0

http://www.scopus.com/inward/record.url?eid=2-s2.0-84884289296\&partnerID=tZOtx3y1

[46] Poudyal, M. and Babel, S. (2015) Removal of Fluoride using Granular Activated Carbon and Domestic Sewage Sludge. Proceedings of the 4th International Conference on Informatics, Environment, Energy and Applications, Pattaya, 28 March 2015, 139-143.

[47] Yadav, A.K., Abbassi, R., Gupta, A. and Dadashzadeh, M. (2013) Removal of Fluoride from Aqueous Solution and Groundwater by Wheat Straw, Sawdust and Activated Bagasse Carbon of Sugarcane. Ecological Engineering, 52, 211-218.

http://dx.doi.org/10.1016/j.ecoleng.2012.12.069

[48] Sinha, S., Pandey, K., Mohan, D. and Singh, K.P. (2003) Removal of Fluoride from Aqueous Solutions by Eichhornia crassipes Biomass and Its Carbonized Form. Industrial \& Engineering Chemistry Research, 42, 6911-6918. http://dx.doi.org/10.1021/ie030544k

[49] Sathish, R.S., Raju, N.S.R., Raju, G.S., Nageswara Rao, G., Kumar, K.A. and Janardhana, C. (2007) Equilibrium and Kinetic Studies for Fluoride Adsorption from Water on Zirconium Impregnated Coconut Shell Carbon. Separation Science and Technology, 42, 769-788. http://dx.doi.org/10.1080/01496390601070067

Submit or recommend next manuscript to SCIRP and we will provide best service for you:

Accepting pre-submission inquiries through Email, Facebook, LinkedIn, Twitter, etc. A wide selection of journals (inclusive of 9 subjects, more than 200 journals)

Providing 24-hour high-quality service

User-friendly online submission system

Fair and swift peer-review system

Efficient typesetting and proofreading procedure

Display of the result of downloads and visits, as well as the number of cited articles

Maximum dissemination of your research work

Submit your manuscript at: http://papersubmission.scirp.org/

Or contact aces@scirp.org 